\title{
Numerical and Experimental Stress Analysis of a Composite Leaf Spring
}

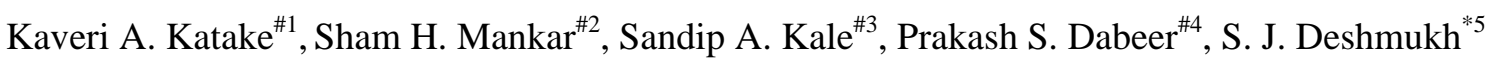 \\ "Trinity College of Engineering and Research, Pune, India \\ ${ }^{1}$ kaveri.katake@gmail.com, ${ }^{2}$ shm9176@gmail.com, ${ }^{3}$ sakale2050@gmail.com, ${ }^{4}$ psdabeer@rediffmail.com \\ *PRM Institute of Technology and Research, Badnera, India \\ 5aryasamir@rediffmail.com
}

\begin{abstract}
Automobile sector is always focusing on enhancing level of comfort, fuel economy, customer satisfaction and safety. Vehicle weight reduction increases the overall fuel efficiency. Use of composite materials has made it possible to reduce the weight of the vehicle, without reduction in load carrying capacity. Now a day's manufacturers and researchers are trying to replace conventional material parts with composites. The composite materials have more elastic strain energy storage capacity and high strength to weight ratio as compared to steel. This paper is related to Numerical and experimental strength analysis of suspension leaf springs for a light motor vehicle made of composite materials. Two materials Glass Fiber Reinforced Plastic (GFRP) and Carbon Fiber Reinforced Plastic (CFRP) are selected for manufacturing of leaf spring. The strength of these composite depends on angle orientation, volume to weight ratio of reinforcement and length to depth ratio of fiber. In this work two leaf springs made of GFRP and a sandwich of CFRP and GFRP are developed. Numerical and experimental static stress analyses are carried out for these two springs. These results are compared with analytical results of conventional metal spring. The comparison shows that composite material springs have compatible strength to withstand load. Comparative results for weight, cost and deformation are presented at the end of the paper.
\end{abstract}

Keywords - CFRP, GFRP, Leaf spring

\section{INTRODUCTION}

Investigation of composite material in the early 1960's failed to yield the production facility because of inconsistent fatigue performance and absence of strong need for mass reduction [3]. Researches in the area of automobile components have been receiving considerable attention now [2]. The automobile manufacturers and parts makers have been attempting to reduce the weight of the vehicles in recent years. Now a day composite materials play an important role in automotive as well as industrial applications [12-15]. The composite materials has many useful defined properties like, lightweight, corrosion resistance, high mechanical and fatigue performance, more elastic strain energy storage capacity and high strength to weight ratio compared to steel. Due to which high level of riding comfort, fuel efficiency is achievable. Weight reduction is achieved by the introduction of better material, manufacturing processes and design optimization. Fiber reinforced composite with polymer based matrix has a required properties as like the conventional materials. It improves fuel efficiency as well as ride qualities [6]. As the composite materials have more elastic strain energy storage capacity and high strength to weight ratio as compared to steel, the composite material offer opportunities for significant weight saving. The composite material is used for parts like bumper, axles, roofs of vehicle where significant weight reduction is possible. The suspension leaf spring is one of the product in which weight reduction is possible. As it accounts $10 \%-20 \%$ of the unsprung weight [1]. Composite materials have made it possible to reduce the weight of leaf spring without any reduction in load carrying capacity [7-11]. This work is focusing on the implementation of composite materials by replacing steel in conventional leaf springs of a suspension system. Therefore analysis of composite material leaf springs has become essential in showing the comparative results with conventional leaf springs [4]. M. M. Patunkar, et al, studied a comparative analysis between steel leaf spring and a composite leaf spring is done under the same static load condition. Deflection and stresses of steel leaf spring and composite leaf spring are to be analyzed [5].

GFRP and CFRP are appropriate light weight materials for manufacturing of leaf spring. The main objective of this work is to compare the stiffness, load carrying capacity, weight and cost of glass fiber composite leaf spring with sandwich of glass and carbon fiber leaf spring. The finite element analysis is carried out for the steel as well as two composite springs. 


\section{A. Material Selection}

\section{Design AND DeVelopment Of LEAf SPRING}

The material selection criteria is important in design of leaf spring. In this work, GFRP and CFRP are used for the leaf spring. Two leaf spring models made from GFRP and a sandwich of GFRP and CFRP material are developed. In sandwich leaf spring $30 \%$ of carbon fiber is used and the comparative study is made between two models of leaf spring and then with steel leaf spring.

B. Properties of Composite Material

Table I. gives the properties of materials used for making these two models,

TABLE I. PROPERTIES OF MATERIAL

\begin{tabular}{|l|l|l|l|}
\hline Sr. No & Properties of Material & GFRP & CFRP \\
\hline 1. & $\begin{array}{l}\text { Tensile Modulus along X-direction } \\
(\mathrm{MPa})\end{array}$ & 34000 & 41270 \\
\hline 2. & Tensile Modulus along Y-direction (MPa) & 6530 & 7350 \\
\hline 3. & Tensile Modulus along Z-direction (MPa) & 6530 & 7350 \\
\hline 4. & Compressive Strength of material (MPa) & 450 & 430 \\
\hline 5. & Poisson's ratio & 0.217 & 0.36 \\
\hline 6. & Mass Density of the material $\left(\mathrm{g} / \mathrm{cm}^{3}\right)$ & 2.66 & 1.58 \\
\hline
\end{tabular}

\section{Development of leaf springs}

In this work, leaf springs with constant cross section area are designed for light motor vehicle. Total load taken by the vehicle is 1.5 ton. It is assumed that the total load is equally shared by each of the four wheels of a vehicle. In this work, mono leaf is considered for analysis purpose. The specifications for developed models are as follow,

TABLE II. SPECIFICATIONS OF LEAF SPRINGS

\begin{tabular}{|l|l|l|l|}
\hline Sr. No. & \multicolumn{1}{|c|}{ Parameters } & $\begin{array}{c}\text { Glass Fiber } \\
\text { leaf spring }\end{array}$ & $\begin{array}{c}\text { Sandwich } \\
\text { leaf spring }\end{array}$ \\
\hline 1. & Total length of spring $(\mathrm{mm})$ & 980 & 980 \\
\hline 2. & No. of full length leaf & 01 & 01 \\
\hline 3. & Thickness of leaf $(\mathrm{mm})$ & 18 & 18 \\
\hline 4. & Width of leaf spring $(\mathrm{mm})$ & 80 & 80 \\
\hline 5. & Maximum load on spring $(\mathrm{N})$ & 3678.75 & 3678.75 \\
\hline 6. & Weight $(\mathrm{kg})$ & 2.2 & 2.4 \\
\hline
\end{tabular}

The glass fiber leaf spring consists of 35 layers is developed. Sandwich leaf spring consists of 12 layers of carbon fiber and 23 layers of glass fiber, is developed.

\section{Finite Element ANalysis of LeAf SPRING}

The modeling of composite leaf spring is done with CATIA V5. For the finite element analysis, ANSYS 14.5 is selected due to its simplicity and quick results. The static structural analysis is performed for both the leaf springs.

The boundary conditions used for analysis are as follow,

TABLE III. BOUNDARY CONDITIONS

\begin{tabular}{|c|c|c|c|}
\hline \multirow[t]{2}{*}{ Sr. No. } & \multirow[t]{2}{*}{ Along Axis } & \multicolumn{2}{|c|}{ Translational Motion } \\
\hline & & Free & Fixed \\
\hline 1. & $\mathrm{X}$ - axis & At one eye end & At one eye end \\
\hline 2. & Y-axis & Free & -- \\
\hline 3. & Z- axis & -- & Fixed \\
\hline
\end{tabular}


Fig. 1 shows the meshing of leaf spring.

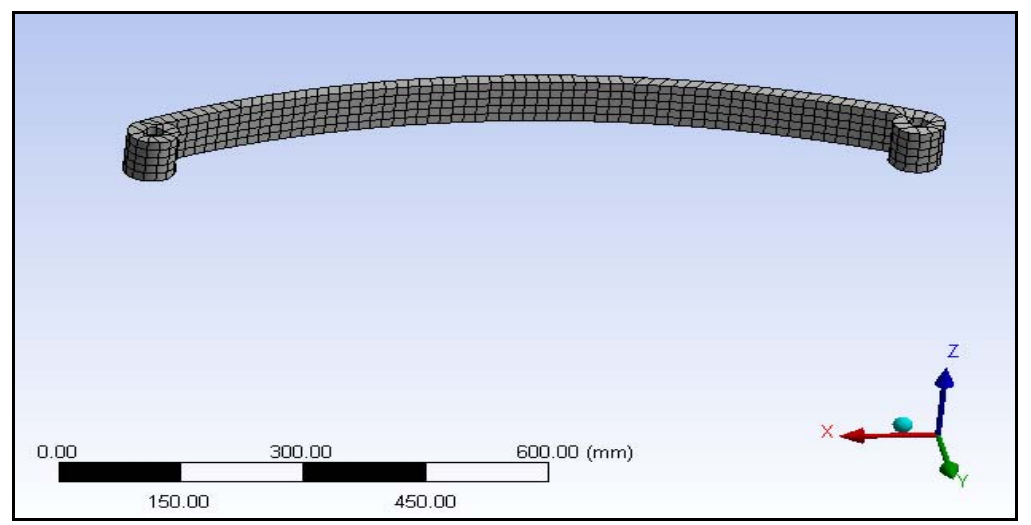

Fig. 1. Meshing of leaf spring.

\section{A. Analysis of steel leaf spring}

Fig. 2 show the stress analysis results for steel leaf spring. The maximum stress induced in the conventional mono leaf spring is $179.62 \mathrm{MPa}$. Fig.3 shows total deformation occured in the steel leaf spring. The maximum deformation observed is $38.98 \mathrm{~mm}$.

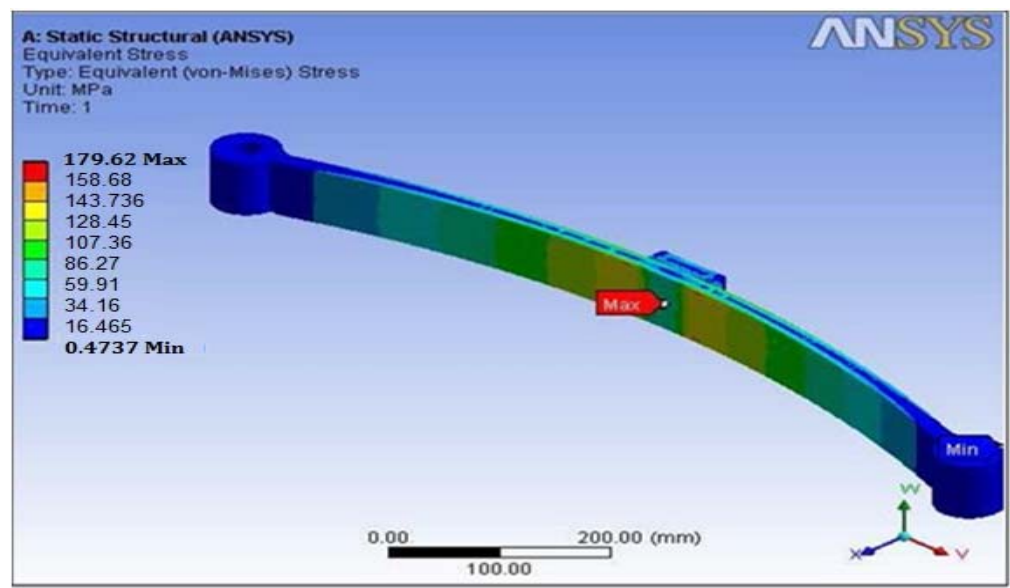

Fig. 2. Stress analysis of steel leaf spring.

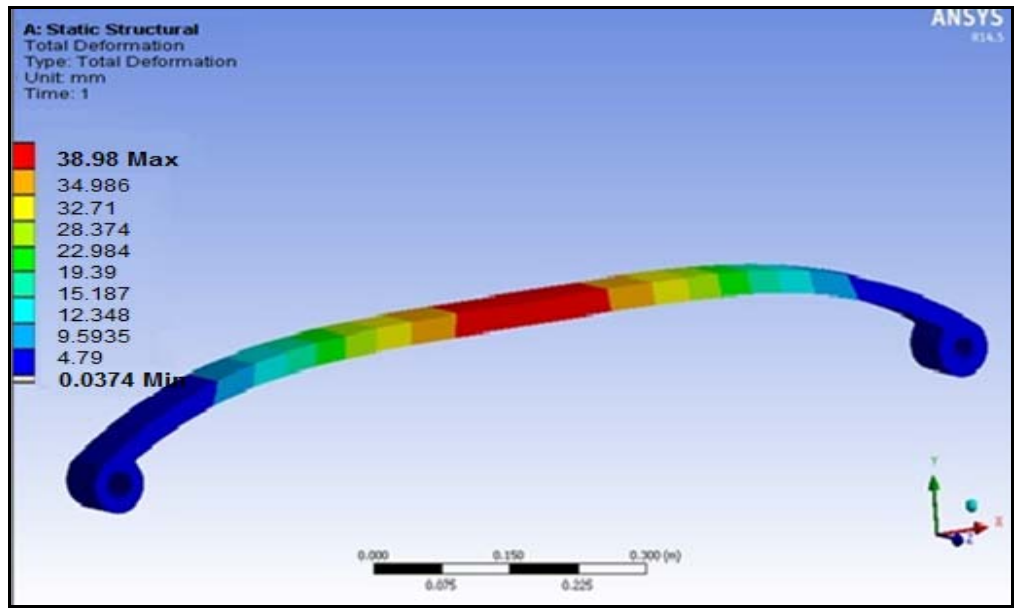

Fig. 3. Total deformation of steel leaf spring.

\section{B. Analysis of GFRP leaf spring}

Fig.4 gives maximum stress produced in the GFRP composite leaf spring and it is $149.52 \mathrm{MPa}$. Stress value is maximum at center and at eye ends. Fig.5 gives total deformation occurs in leaf spring as $49.21 \mathrm{~mm}$. 


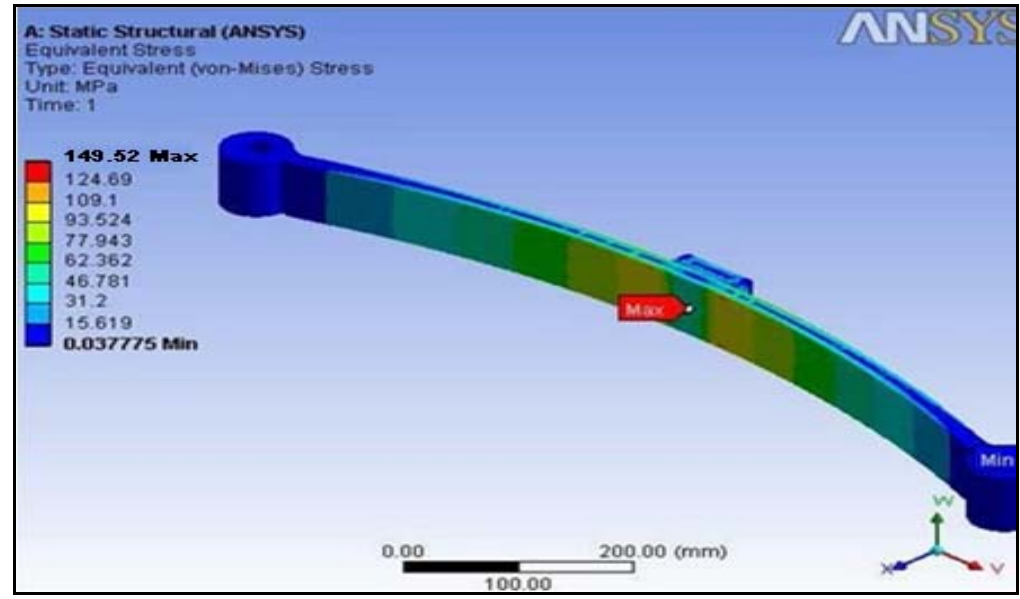

Fig. 4. Stress analysis of GFRP leaf spring.

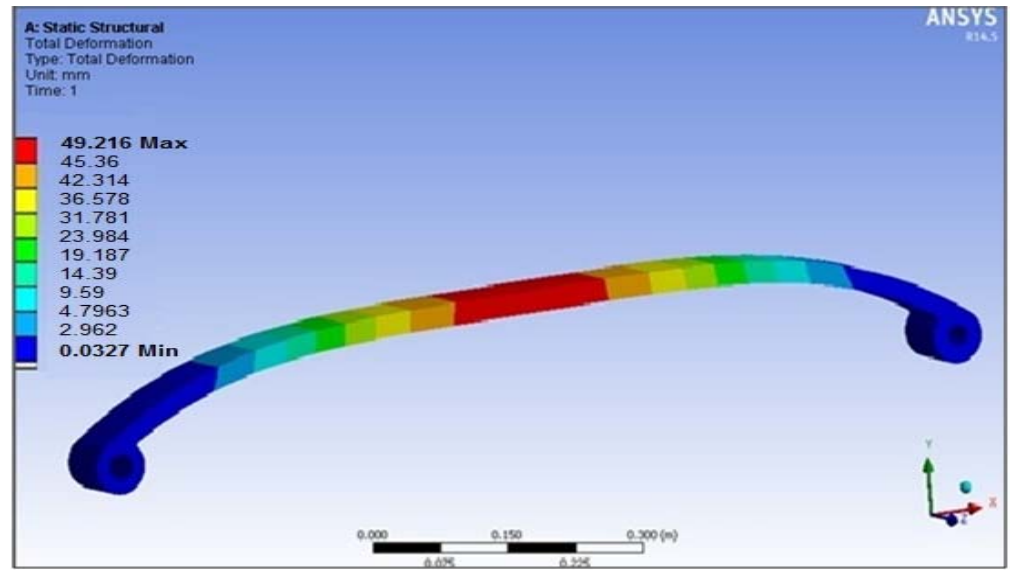

Fig. 5. Total deformation of GFRP leaf spring.

\section{Analysis of sandwich leaf spring}

Fig.6 shows stress analysis for the sandwich leaf spring. The maximum stress produced is 140.27 MPa. Fig.7 shows total deformation occurred in sandwich leaf spring is $43.17 \mathrm{~mm}$.

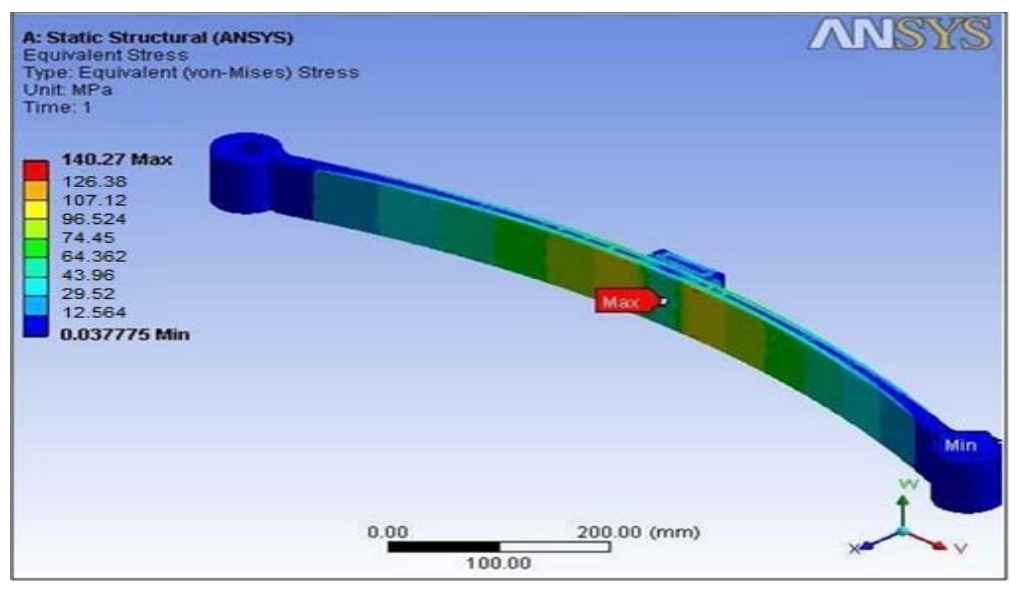

Fig. 6. Stress analysis of sandwich leaf spring. 


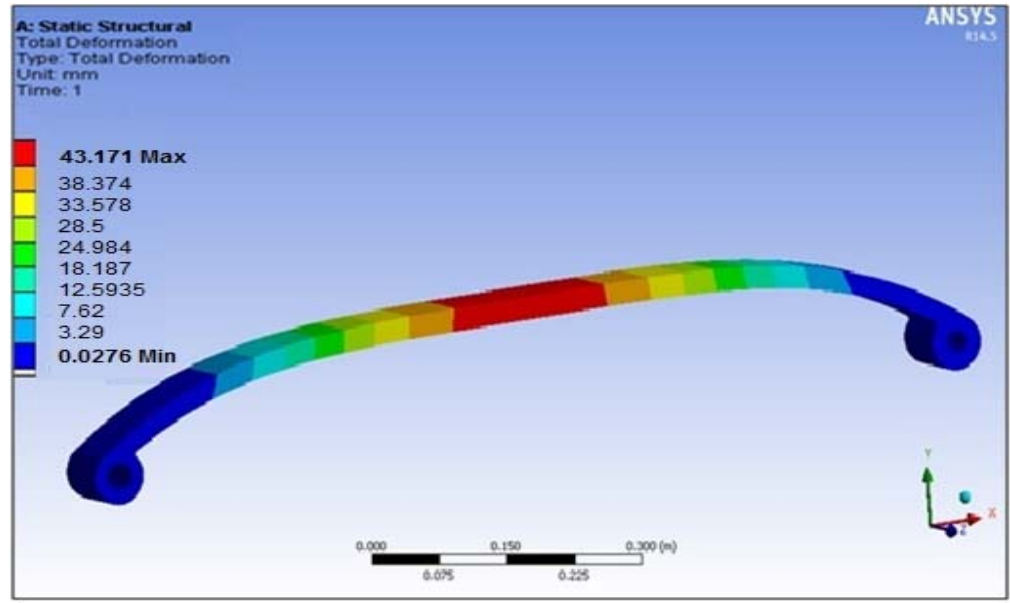

Fig. 7. Total deformation of sandwich leaf spring.

Total deformation induced in GFRP and sandwich leaf spring is higher as compare to steel leaf spring. The deformation occurs in sandwich leaf spring is lesser than the GFRP leaf spring, but the difference between them is less as compare to the conventional leaf spring. Stress produced in steel leaf spring is maximum than the composite leaf springs. The stress produced in sandwich leaf spring is less as compare to the GFRP leaf spring.

\section{EXPERIMENTAL ANALYSIS}

The static test is conducted on the universal testing machine. The GFRP leaf spring model is placed on the fixture. By keeping the one end fixed and other end free reading for deflection and stresses are obtained. The same procedure is used for sandwich leaf spring. Fig.8 shows the test setup used for the static test.

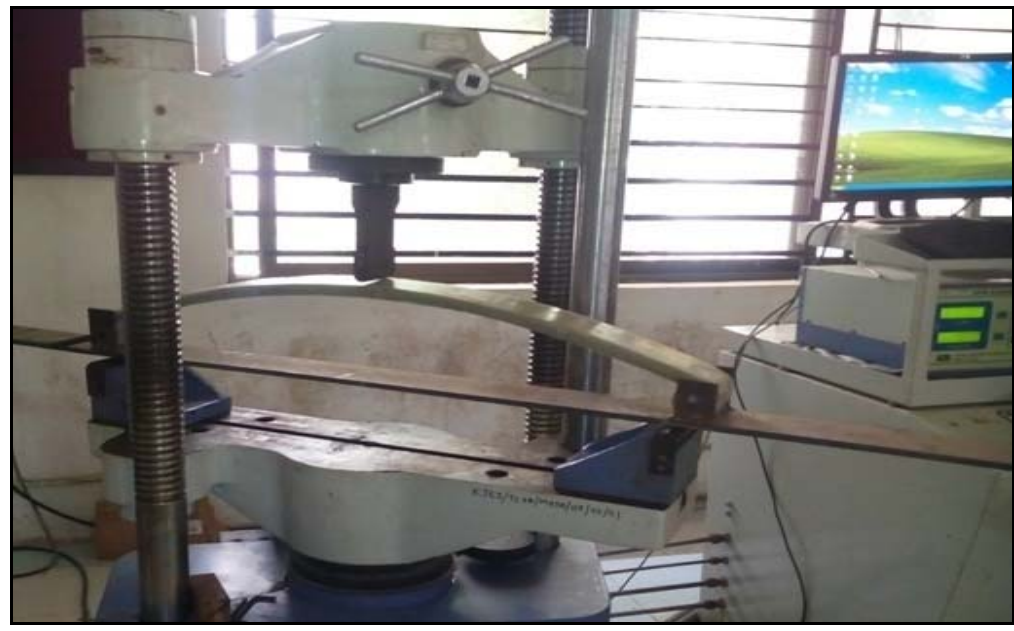

Fig. 8. Test setup for static test.

\section{Results And Discussion}

The result obtained from experimental and analytical analysis are presented in this section. Fig. 9 shows spring deflection vs. load values. From the figure, it is observed that the deflection produced in steel leaf spring is less as compare to the GFRP and sandwich leaf spring. The composite leaf springs shows the deflection values within limit. GFRP leaf spring having maximum deformation than the sandwich leaf spring. 


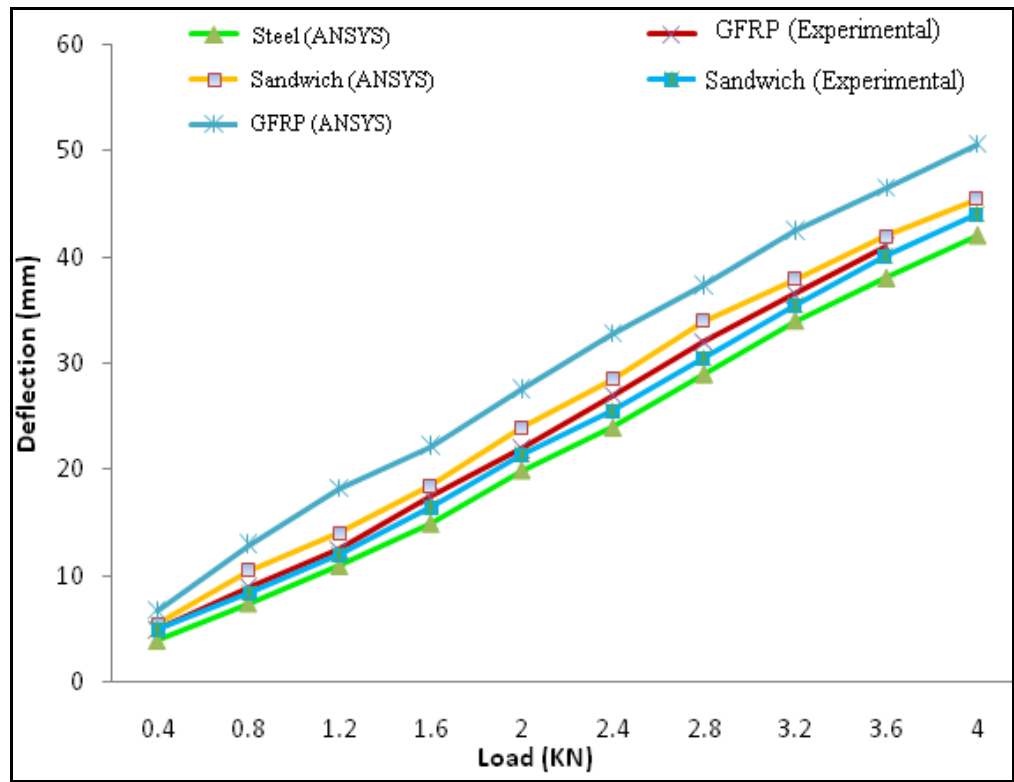

Fig. 9. Spring deflection vs. load.

Fig.10 shows load vs. stress values obtained from the experimental as well as analytical analysis. The sandwich leaf spring shows the lesser stresses than the GFRP and steel leaf spring. Both composite leaf spring shows minimum stresses than the steel leaf spring. Steel leaf spring shows maximum value for stress.

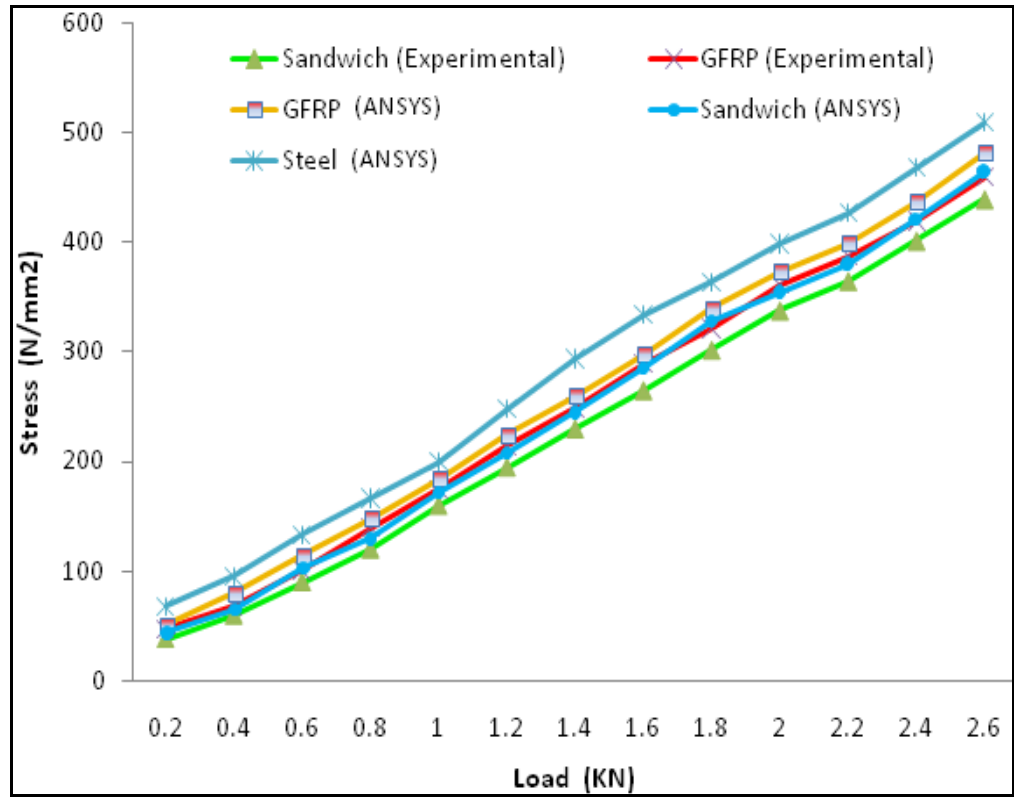

Fig. 10. Stress induced in spring at various loads.

Fig.11 shows the comparative explanation about the weight, cost, stiffness and deformation of the conventional steel leaf spring, glass fiber leaf spring and sandwich of glass and carbon fiber leaf spring. 


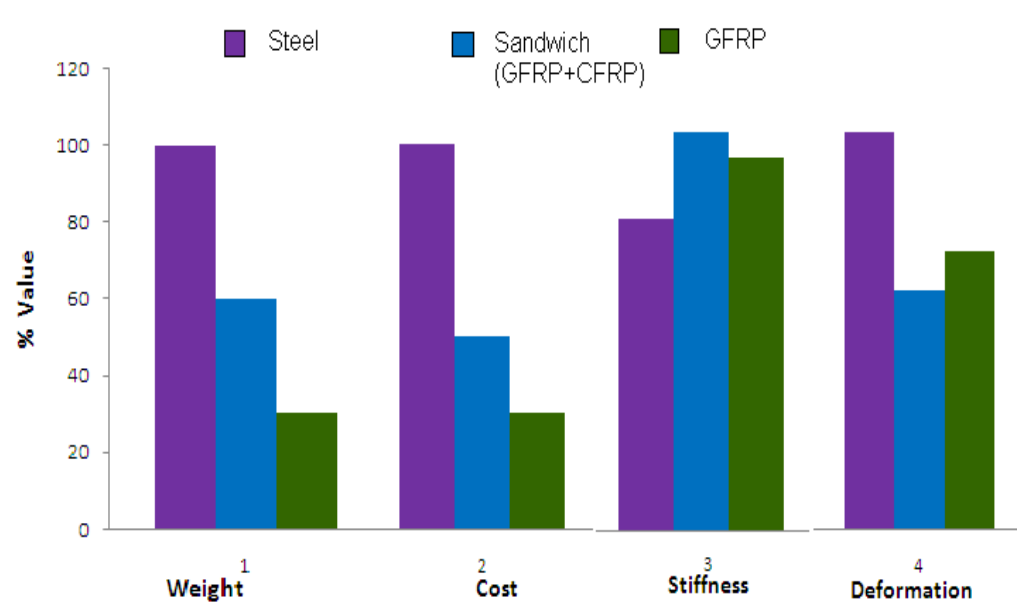

Fig. 11. Comparision between conventional and composite material.

\section{CONCLUSION}

It is observed that GFRP leaf spring is having higher deformation than the sandwich and steel leaf spring. Stress developed in sandwich leaf spring is lesser than the GFRP and steel leaf spring. The stiffness of carbon fiber is more as compare to both the spring. But due to addition of small amount of carbon fiber increases the strength of sandwich leaf spring. The reduction in weight of composite leaf springs is $70 \%$ than the conventional steel leaf spring. It means weight reduction is achieved for same loading condition. The cost of glass fiber leaf spring is lesser than the sandwich leaf spring and sandwich leaf spring having less cost as compare to the steel leaf spring, the cost reduction is also achieved. The strength of sandwich leaf spring is higher as compared GFRP and steel leaf spring.

\section{REFERENCES}

[1] Dara Ashok, M.V. Mallikarjun, "Design and Structural Analysis of Composite Multi Leaf Spring”, IJEED, Issue 2, 30-37pp, July 2012.

[2] Sachin Kr. Patel, A.K. Jain, “A Review of Effect of Material on Fatigue Life of Leaf Spring”, VSRD-MAP, Vol-2(4), 161-165pp, 2012.

[3] Vinkel Arora, Gian Bhushan, "Eye design analysis of single leaf spring in automotive Vehicles using CAE tools”, International Journal of Applied Engineering and Technology, Vol-1, 88- 97pp, Oct-Dec 2011.

[4] M. M. Patunkar, D. R. Dolas, "Modeling and Analysis of Composite Leaf Spring under the Static Load Condition by using FEA", IJMIE, Volume -1, 1-4pp, 2011.

[5] M. Raghavedra, Syed Altaf Hussain, "Modeling and Analysis of Laminated Composite Leaf Spring under the Static Load Condition by using FEA”, IJMER Vol-2, 1875-1879pp, Jul-Aug 2012.

[6] M.Venkatesan, D.Helmen Devraj, "Design and analysis of composite leaf spring in Light vehicle”,(IJMER), Vol.2,215-216pp, Jan-Feb 2012,

[7] Gulur Siddaramanna Shiva Shankar, Sambagam vijayarangan, "Mono Composite Leaf Spring for Light Weight Vehicle - Design, End Joint Analysis and Testing”, ISSN 1392-1320 Materials Science (Medžiagotyra). Vol. 12, No. 3. 2006.

[8] Kumar Krishnan and Aggarwal M.L, "A finite element analysis approach for analysis of a multi leaf spring using CAE tools", ISSN JOURNAL , Vol. 1(2), 92-96 pp, Feb 2012.

[9] N. P. Dhoshi, N.K.Ingole, "Analysis and Modification of Leaf Spring of Tractor Trailer Using Analytical and Finite Element Method", Vol.1, Issue.2, pp-719-722.

[10] A S Singha and Vijay Kumar Thakur, "Mechanical properties of natural fibre reinforced polymer composites”, Bull. Mater. Sci., Vol. 31, No. 5, 791-799 pp ,October 2008.

[11] Bhushan B. Deshmukh, Santosh B. Jaju, "Design and Analysis of Fiber Reinforce polymer (FRP) Leaf Spring”, Int J Engg Techsci, Vol 2(4), 289-291pp, 2011.

[12] Kamal Sethi, "Investigation of Damaged Glass Fiber Reinforced Polymer Composites In 3-Point Bending”, Thapar Institute of Engineering \& TechnologyPatiala-147 004, India.

[13] Heinz-Gunter Reichwein, Paul Langemeier, "Light, Strong and Economical - Epoxy Fiber-Reinforced Structures for Automotive Mass Production”, http://www.lcc.mw.tum.de/en/department/anwendungsgebiete/automotive.

[14] John Delmonte, “Historical Perspectives of Composites”, International Encyclopedia of Composites, New York: VCH Publishers, 1990.

[15] Strong, A. Brent, Dearborn, “Fundamentals of Composites Manufacturing”, MI: Society of Manufacturing Engineers, 1989. 